\title{
CARACTERIZAÇÃO PÓS-COLHEITA DE FRUTOS DE BANANEIRA 'BRS PLATINA' DE PRIMEIRO CICLO, SOB REGULAÇÃO DO DÉFICIT DE IRRIGAÇÃO ${ }^{1}$
}

\author{
ARIANE CASTRICINI ${ }^{2}$, EUGENIO FERREIRA COELHO ${ }^{3}$, \\ MARIA GERALDA VILELA RODRIGUES ${ }^{2}$, RODRIGO CARDOZO COUTINHO ${ }^{4}$
}

RESUMO- O trabalho teve como objetivo a caracterização pós-colheita de bananas cv BRS Platina (PA4244), que é um híbrido tetraploide (AAAB) desenvolvido pela Embrapa. As mesmas foram produzidas no norte de Minas Gerais, com redução das lâminas (L) de água utilizadas na irrigação,a partir dos cinco meses após o plantio. Foram sete os tratamentos avaliados, com combinações de redução da lâmina $(55 \%, 70 \%$ e $85 \%)$ nas fases II e III de desenvolvimento da planta ( 5 a 7 meses, e 7 a 12 meses após o plantio), caracterizados quanto a: teor de sólidos solúveis totais (sst), despencamento, firmeza da polpa, comprimento e diâmetro do fruto, relação polpa/casca e coloração da casca, definida pelos parâmetros $\mathrm{L}^{*}, \mathrm{C}^{*} \mathrm{e}^{\mathrm{o}} \mathrm{h}$, avaliados quando os frutos estavam totalmente amarelos. O teor de sólidos solúveis totais foi maior nos frutos do tratamento T3, onde houve redução da lâmina de irrigação na fase II (floração) para $70 \%$ da ETc. A maior relação polpa/ casca foi obtida quando a ETc foi reduzida em $25 \%$ na fase III, resistência ao despencamento. Os frutos mais firmes foram produzidos quando a ETc na fase II foi reduzida em $45 \%$; já o menor despencamento foi obtido quando esta redução foi de $45 \%$ e $30 \%$ na fase II, e de $30 \%$ na fase III. Os maiores (comprimento e diâmetro) e mais pesados frutos foram produzidos na ausência de déficit hídrico durante todo o ciclo da cultura. Termos para Indexação: Musa spp. (AAAB), manejo de irrigação, pós-colheita.

\section{POST HARVEST CHARACTERIZATION OF BANANAS 'BRS PLATINA' FIRST CYCLE UNDER REGULATION OF IRRIGATION DEFICIT}

\begin{abstract}
The study had as objective the post harvest characterization of bananas cultivar BRS Platina that is a tetraployd hybrid AAAB developed by Embrapa. The crop was grown at North of Minas Gerais with reduction of irrigation water depths (L) from five months after planting. Seven treatments were evaluated with different combinations of water depth reductions $(55 \%, 70 \%$ and $85 \%)$ during two phases of crop development (5 to 7 months and 7 to 12 months after planting) where fruits were characterized when completely yellow by: total soluble solids (tss), dropping, pulp strength, length and fruit diameter, pulp/peel ratio and color of peel $\left(\mathrm{L}^{*}, \mathrm{C}^{*}\right.$ and $\left.{ }^{\circ} \mathrm{h}\right)$. The total soluble solids was larger on fruits of treatments $\mathrm{T} 3$ and T5, where there was reduction of irrigation water depth only in the phase II (flowering) for $70 \%$ and $85 \%$ of ETc. The larger pulp/peel relationship and the resistance to drop were observed when ETc was reduced by $25 \%$ in phase III (from the beginning of fruit growth to harvest). Stronger fruit were produced when ETc was reduced about $45 \%$. The smaller fruit dropping was verified when the reduction was $45 \%$ and $30 \%$ in phase II and about $30 \%$ on phase III. The larger fruits, as in length as in diameter, the heaviest ones were produced with no water deficit along the whole crop cycle.
\end{abstract}

Index terms: Musa spp. (AAAB), irrigation scheduling, post-harvest.

\footnotetext{
${ }^{1}$ (Trabalho 118-12). Recebido em: 23-03-2012. Aceito para publicação em: 25-07-2012. Trabalho financiado pela Fapemig, CNPq e Embrapa, processo 474786/2011-0 e 03.10.6.21.00.02.

${ }^{2}$ Enga Agrônoma, Dra., Pesquisadora, EPAMIG Norte de Minas, FEGR, Bolsista Fapemig, Nova Porteirinha - MG. E-mails: ariane@epamig.br; magevr@epamig.br

${ }^{3}$ Eng $^{\circ}$ Agrícola, Dr., Pesquisador Embrapa Mandioca e Fruticultura, Cruz das Almas - BA. E-mail: eugenio@cnpmf.embrapa.br ${ }^{4}$ Discente de Agronomia, Unimontes, Janaúba - MG.
} 


\section{INTRODUÇÃO}

A região norte de Minas Gerais é grande produtora de banana, entretanto a produção comercial só é possível sob irrigação em razão da baixa precipitação anual e da alta taxa de evapotranspiração. Na região, produz-se basicamente 'Prata-Anã', obrigatoriamente sob irrigação, sendo o principal polo de produção de banana do Estado e o principal polo de produção de banana 'Prata-Anã' do País. As incertezas climáticas associadas à possibilidade de elevação da temperatura da terra confrontam a crescente necessidade de uso de água na agricultura. A agricultura irrigada, que já se coloca como o maior consumidor de água doce, precisa adequar-se às dinâmicas do clima quanto à redução dos recursos hídricos. Uma das ações que podem contribuir de forma relevante é o manejo da água para irrigação, de forma a promover o uso racional da mesma, podendo ser feito por diversas maneiras, dentre as quais o uso do déficit regulado, uma técnica que vem sendo aplicada em fruteiras como os citros (DOMINGO et al., 1996; GONZÁLEZ-ALTOZANO;CASTEL, 1999) e mangueira (COTRIM et al., 2011), porém ainda não definida para bananeiras. Nesse método, objetiva-se reduzir o aporte de água comumente calculado para a cultura, sem reduzir significativamente a produtividade e a qualidade da produção da mesma. $\mathrm{O}$ efeito da redução no rendimento da cultura, em consequência da redução regulada de água, pode ser mitigado ainda com o uso de cultivares mais tolerantes a estresses hídricos. A redução do aporte de água por determinado tempo, em determinadas fases da cultura, pode afetar as características químicas e físicas do produto. Assim, torna-se necessário avaliar os efeitos dessa forma de manejo da água de irrigação tanto nos aspectos produtivos quanto nos de pós-colheita.

A banana 'BRS Platina' (ou PA42-44) é um híbrido tetraploide (AAAB) desenvolvido pela Embrapa Mandioca e Fruticultura, a partir do cruzamento entre 'Prata-Anã' (AAB) x M53 (AA). Diferencia-se da 'Prata-Anã' por ser resistente à Sigatoka-amarela e ao mal-do-panamá (SILVA et al., 2008), estando ainda em avaliação quanto à resistência à Sigatoka-negra. Comparada à 'Prata-Anã', apresenta frutos maiores; de coloração verde mais clara; bom sabor; formato plano, o que lhe confere facilidade para embalar (DONATO, 2003); além de melhores características de dimensão, acidez titulável e menor doçura (OLIVEIRA, 2010). Os frutos da 'BRS Platina' assemelham-se aos da 'Prata-Anã', na forma, tamanho e sabor, porém devem ser consumidos com a casca um pouco mais verde, à semelhança das variedades do subgrupo Cavendish (SILVA et al., 2008).

A principal desvantagem da 'BRS Platina', relatada por diversos autores (DONATO, 2003; LIMA et al.; 2004; LINS, 2005; DONATO et al., 2006; SILVA et al., 2008; PIMENTEL et al., 2010), é a suscetibilidade ao despencamento, característica indesejável, que afeta o manuseio, o transporte e a comercialização, reduzindo o valor comercial e a aceitação dos frutos pelos consumidores

A alta exigência da 'Prata-Anã' em água e nutrientes, além de sua suscetibilidade às principais doenças fúngicas da cultura (Sigatokas-amarela e negra, e mal-do-panamá) têm resultado na busca por novas alternativas pelos produtores do norte de Minas Gerais. Um dos genótipos que se mostram promissores é a 'BRS Platina' (apesar de ainda em estudo quanto à resistência à Sigatoka-negra) que, entretanto, necessita ser mais bem avaliada na região, principalmente quanto ao manejo. De acordo com Matsura et al. (2004), os atributos de sabor, vida útil e aparência são os mais importantes na escolha ou na compra de bananas e, consequentemente, da variedade, segundo os consumidores entrevistados naquele estudo. $\mathrm{O}$ objetivo do presente trabalho foi caracterizar, na pós-colheita, os frutos de bananeira 'BRS Platina' produzidos sob manejo de irrigação com uso da técnica da regulação do déficit de irrigação (RDI).

\section{MATERIAL E MÉTODOS}

O experimento foi conduzido na Fazenda Experimental do Gorutuba, da Empresa de Pesquisa Agropecuária de Minas Gerais, localizada em Nova Porteirinha, norte de Minas Gerais (EPAMIG/ URENM), nas coordenadas geográficas $15^{\circ} 46^{\prime}$ $38,98^{\prime \prime} \mathrm{S}$ e $43^{\circ} 17^{\prime} 22,06^{\prime \prime}$ com uma altitude de 537 metros. A cultura foi plantada no espaçamento 3,0 x 2,5 m, sob irrigação por microaspersão, com um emissor de vazão $70,0 \mathrm{~L} \mathrm{~h}^{-1}$ para quatro plantas, e conduzida conforme recomendações feitas para o cultivo da 'Prata-Anã' na região. O manejo da água de irrigação foi feito utilizando a frequência de dois dias, a partir da evapotranspiração da cultura (ETc), que foi determinada em função da evapotranspiração de referência (ETo) obtida pela evaporação do tanque classe A (ALLEN et al., 1998).

Todas as plantas foram irrigadas com $100 \%$ da ETc (irrigação plena), na fase I (do plantio ao quinto mês após o plantio - MAP, ou fase vegetativa). A partir daí, os sete tratamentos foram diferenciados com a redução das lâminas de irrigação obtidas em trabalhos de pesquisa como correspondentes às 
produtividades máximas da bananeira, na fase II (do quinto ao sétimo MAP, ou fase entre a diferenciação floral e a floração) e na fase III (do sétimo ao décimo segundo MAP, ou fase entre a floração e a colheita): T1 - 55\% da ETc na fase II e irrigação plena (100\% ETc) na fase III; T2 - irrigação plena na fase II e $55 \%$ da ETc na fase III; T3 - 70\% da ETc na fase II e irrigação plena na fase III; T4 - irrigação plena na fase II e $70 \%$ da ETc na fase III; T5- $85 \%$ da ETc na fase II e irrigação plena na fase III; T6 - irrigação plena fase II e 85\% da ETc na fase III; T7 - irrigação plena em todas as fases de desenvolvimento da planta.

A colheita foi feita quando os frutos atingiram o ponto de maturidade comercial: frutos com máximo crescimento, ainda ligeiramente quinados, e com casca totalmente verde, ou seja, no estádio 2 da escala de Loeseche (1950), que apesar de antiga continua sendo utilizada. Para as avaliações de pós-colheita, utilizou-se apenas a segunda penca de cada cacho, que foi levada ao Laboratório de Pós-Colheita da URENM onde permaneceu em condições ambientais até o amarelecimento da casca para procedimento das avaliações. Quando os frutos atingiram o estádio de amadurecimento 6 da mesma escala (casca 100\% amarela), foram analisados. Para fins estatísticos, foi utilizado o delineamento inteiramente casualizado, com oito repetições (oito frutos retirados da segunda penca) por tratamento, para todas as características estudadas. As avaliações de diâmetro, firmeza e coloração foram sempre realizadas na parte central (zona equatorial) dos frutos.

O estádio 6 de maturação considera o percentual da casca na cor amarela (100\%), mas não a tonalidade. Esta foi determinada através do Colorímetro Minolta, modelo Chroma meter CR 400, sistema L $\mathrm{C}$ H. O equipamento expressa a cor através de três componentes: luminosidade $\left(\mathrm{L}^{*}\right)$, que oscila entre 0 (cores escuras ou opacas) e 100 (cores brancas ou de máximo brilho); cromaticidade ou pureza da cor (C*), cujos valores baixos representam cores impuras (acinzentadas), e os elevados, as cores puras; ângulo de tonalidade ou cor verdadeira $\left({ }^{\circ} \mathrm{Hue}\right)$, que varia entre $0^{\circ}$ e $360^{\circ}$, sendo que o ângulo $0^{\circ}$ corresponde à cor vermelha, $90^{\circ}$ à cor amarela, $180^{\circ} \mathrm{ou}-90^{\circ}$ à cor verde, $270^{\circ} \mathrm{ou}-180^{\circ}$ à cor azul, e passa de vermelho a negro em $360^{\circ}$ (MORAIS et al., 2002). A avaliação de sólidos solúveis totais foi feita por leitura direta em refratômetro manual, com resultados expressos em ${ }^{\circ}$ Brix (INSTITUTO ADOLFO LUTZ,1987); a resistência ao despencamento expressa em $\mathrm{N}$ foi feita por meio de um despencador acoplado a um dinamômetro digital para medir a força necessária para desprender o fruto do pedúnculo (PIMENTEL et al., 2010); a firmeza dos frutos expressa em $\mathrm{N}$ foi determinada na região equatorial dos frutos com casca, medida com o uso de um penetrômetro digital. A massa média dos frutos foi obtida após pesagens em balança digital, e o resultado, expresso em gramas. Foram avaliados o comprimento do fruto $(\mathrm{cm}) \mathrm{com}$ medições utilizando fita métrica na curvatura externa do fruto, desde a base da inserção do pedúnculo até a extremidade do mesmo. O diâmetro do fruto $(\mathrm{mm})$ foi obtido com o auxílio de paquímetro digital, na região mediana dos mesmos. A relação polpa/casca foi obtida pela razão entre a massa do fruto sem casca e pela massa da casca.

Os dados resultantes das avaliações foram processados com auxílio do software SAEG 9.1 (2007) para realização de análise de variância, e as diferenças entre os tratamentos, identificadas pelo teste de Tukey, a 5\% de significância. Os dados que não apresentaram distribuição normal pelo teste de Lilliefors, foram transformados para $\log \mathrm{x}$.

\section{RESULTADOS E DISCUSSÃO}

De acordo com a análise de variância, que pode ser vista nas Tabelas 1 e 2, houve diferença significativa entre os tratamentos, para as características estudadas.

Todas as plantas foram conduzidas com irrigação plena da fase vegetativa (fase I), compreendida entre o plantio e o quinto mês. Os tratamentos, ou a RDI nas fases II (do quinto ao sétimo mês - compreendida entre a diferenciação floral e a floração) e III (do sétimo ao décimo segundo mês - compreendida entre a floração e a colheita), influenciaram a massa, o comprimento, o diâmetro, a relação polpa/casca, a resistência ao despencamento, a firmeza e o teor de sólidos solúveis dos frutos da segunda penca da banana 'Platina' (Tabela 3).

Conforme verificado por Silva et al. (2006), as amostras de banana que obtiveram aceitação por maior número de consumidores foram aquelas constituídas por frutos que se encontravam nos estádios de amadurecimento 5 e 6 . Em função disto, optou-se por caracterizar os frutos que atingiram o estádio 6 de maturação.

O melhor rendimento em massa média dos frutos $(167,8 \mathrm{~g})$ foi obtido no $\mathrm{T} 7$, onde não houve restrição hídrica, enquanto os piores resultados foram observados principalmente quando houve restrição da irrigação na fase III (T2, T4 e T6), além do T3. Da mesma forma, os frutos mais longos $(21,7 \mathrm{~cm})$ e com maior diâmetro $(45,1 \mathrm{~cm})$ foram obtidos no $\mathrm{T} 7$, com menores valores para comprimento quando restrita a irrigação também na fase III. Este resultado é coerente, já que a massa do fruto tem como 
um de seus componentes seu tamanho (dado pelas dimensões comprimento e diâmetro). A restrição hídrica nas duas fases reduziu tanto o comprimento quanto o diâmetro dos frutos e, consequentemente, a massa, mas reduziu especialmente o comprimento na fase III.

A massa média destes frutos de T7 (167,8 g) foi inferior àquela encontrada por Donato (2006) para o mesmo genótipo $(174,22 \mathrm{~g})$, porém superior à encontrada por Oliveira et al. (2008) e Borges et al. (2011) (89,14g e 141,1 g, respectivamente). Nos outros tratamentos com ausência de restrição hídrica na fase III, exceto em T3, portanto em $\mathrm{T} 1$ e T5, observou-se massa média dos frutos também superior às encontradas por esses autores: 142,7 e $143,4 \mathrm{~g}$, respectivamente.

Dentro das características de cada genótipo, o tamanho dos frutos é, entre outros fatores, dependente do ritmo de emissão foliar e do porte da planta. Uma planta que não passa por estresse hídrico (ou outro estresse) tem maior chance de produzir maiores e melhores frutos, já que o início do crescimento destes se dá ainda na fase de floração. De acordo com Soto Balestero (2000), o crescimento dos dedos por alongamento dos ovários (comprimento) inicia-se quatro dias antes da floração e mantém-se a uma taxa relativamente alta até 30 dias após o florescimento. $\mathrm{O}$ diâmetro aumenta até mais tarde, a depender das condições de cultivo, podendo chegar a 90 dias, sendo fortemente influenciado pelas condições climáticas vigentes no período de floração, como excesso ou deficiência de água no solo. Estas informações são confirmadas pelos resultados obtidos neste experimento, já que os maiores frutos foram obtidos no T7, onde não houve deficiência hídrica em qualquer das fases.

Além de ser componente do rendimento da produção do bananal ( $\left.\mathrm{t} \mathrm{ha}^{-1}\right)$, as dimensões dos frutos compõem os itens de classificação da fruta, resultando no valor final da produção. De acordo com Frutiséries (2000), frutos do subgrupo Prata são classificados em três categorias quanto ao comprimento (classe I) e diâmetro (classe II): Exportação: $>16 \mathrm{~cm}$ e $>38 \mathrm{~mm}$; Primeira: $>14 \mathrm{~cm}$ e $>32 \mathrm{~mm}$; e Segunda: $>12 \mathrm{~cm}$ e $>29 \mathrm{~mm}$, respectivamente. Apesar das diferenças significativas para estas características entre os tratamentos, todos os frutos apresentaram comprimento e diâmetro médios que permitem classificá-los como tipo exportação, o que se deve ao genótipo ser um tetraploide que apresenta frutos grandes. Assim, Donato et al. (2009) e Marques et al. (2011), também caracterizaram os frutos dentro desta faixa de comprimento; no entanto, os frutos avaliados por Marques et al. (2011) apresentaram menor diâmetro que os frutos do presente trabalho. Matsuura et al. (2004), ao entrevistarem consumidores de banana sobre as preferências quanto aos atributos de qualidade, concluíram que o fruto de banana ideal deve possuir tamanho médio (12 a $15 \mathrm{~cm}$ ) ou grande (16 a $19 \mathrm{~cm})$, diâmetro médio (26 a $30 \mathrm{~mm})$ e casca amarelo-média ou amarelo-escura, características estas atendidas pelos frutos de todos os tratamentos: comprimento médio entre 17,2 a 21,9 cm; diâmetro entre 38,2 e 45,1 mm; e casca com coloração amarela (Tabelas 3 e 4). De acordo com Jesus et al. (2004), as características físicas de diâmetro e comprimento também são parâmetros importantes para frutas destinadas ao processamento de produtos desidratados, influenciando o processo de secagem.

A maior relação polpa/casca (Tabela 3) foi verificada nos frutos provenientes do cultivo com redução de $15 \%$ da ETc na fase III (T6), onde há predominância de crescimento dos frutos, sendo finalizada com as colheitas, enquanto o menor valor foi obtido em T7, onde não foi aplicado o déficit. Este resultado pode dar-se tanto pelo aumento da polpa quanto pela redução da massa da casca, e interfere principalmente no rendimento para a indústria. Tal relação é conhecida como "coeficiente de amadurecimento", que é considerado um índice de maturidade (MATSUURA; FOLEGATTI, 2001).

Apesar de, no presente trabalho, as avaliações terem sido feitas com padronização do estádio de amadurecimento (coloração da casca totalmente amarela - estádio 6), as diferenças observadas na relação polpa/casca deram-se pela composição e/ou organização dos tecidos em função dos tratamentos. Apesar de T7 ter apresentado a maior massa de polpa, apresentou também maior massa de casca, com menor percentual da polpa em relação à massa total do fruto (62\%), resultando na menor relação polpa/ casca. Já T6 apresentou massa média de polpa e a menor massa de casca, resultando no maior percentual de polpa em relação à massa total do fruto $(72 \%)$, levando à maior relação polpa/casca.

De acordo com Damatto Jr. et al. (2005), com o amadurecimento, os frutos passam a ter maior porcentagem de polpa, uma vez que a casca perde mais água que esta neste período. Além de perder água para a polpa, a casca da banana perde água para o meio ambiente, pela transpiração, resultando em incremento da relação polpa/casca durante o amadurecimento.

A maior resistência ao despencamento $(23,82$ N) foi observada no T2, onde foi aplicada lâmina de irrigação com redução de $45 \%$ da ETc na fase III (após a floração). As menores resistências ao despencamento foram observadas nos tratamentos submetidos à irrigação plena ou com, no máximo, 
redução de $30 \%$ da ETc na fase III ou de $25 \%$ nas fases II ou III (T4 a T7). De acordo com os padrões de resistência ao despencamento definidos por Pereira et al. (2004), os frutos de T2 foram medianamente resistentes - resistência entre 20 e $60 \mathrm{~N}$ - porém os frutos dos demais tratamentos foram considerados suscetíveis, por apresentarem resistência $<20$ N. O experimento foi conduzido em condições ambientais (simulando a exposição para venda), porém técnicas de pós-colheita, como a refrigeração, podem auxiliar, minimizando o despencamento. De acordo com Oliveira (2010), a temperatura de armazenamento influenciou no despencamento da banana PA 42-44 ('Platina'), sendo que a $15^{\circ} \mathrm{C}$ a resistência foi maior que a $25^{\circ} \mathrm{C}$, embora tenha ocorrido diminuição da resistência ao despencamento dos frutos armazenados nas duas temperaturas à medida que amadureciam.

Corbeña Ruiz (2003) observou que, a partir do estádio 3 de maturação, a resistência ao despencamento decresceu sensivelmente para 'Prata' e SH36-40, atingindo valores de $11 \mathrm{~N}$ e $12 \mathrm{~N}$ no estádio 7 , respectivamente. $\mathrm{O}$ autor atribui este resultado ao maior acúmulo de matéria seca e amido no pedicelo dos materiais com maior resistência e, principalmente, para o SH36-40 (AAAB), a degeneração do tecido parenquimático na região de despencamento, com formação de grandes espaços vazios. Esta característica foi igualmente observada na 'Pioneira', que também é um tetraploide AAAB, e diferente do observado na 'Terra', que é um triploide AAB. Para Pereira et al. (2004), há indícios de que a presença do genoma B (M. balbisiana) propicia maior resistência ao despencamento dos frutos, ao contrário da presença do genoma $\mathrm{A}$ ( $M$. acuminata), o que pode ser um indicativo de que os genes de resistência ao despencamento podem estar associados à espécie $M$. balbisiana. Para Saengpook et al. (2007), uma das razões para o enfraquecimento do pedúnculo pode ser a degradação da pectina, e Esguerra et al. (2009) complementam dizendo que o despencamento está associado com o enfraquecimento e o amaciamento do pedúnculo

Os valores médios de firmeza do fruto, em função do manejo da irrigação, podem ser vistos na Tabela 3. Os frutos produzidos nos tratamentos T2, T3 e T4 apresentaram maior firmeza, sendo estatisticamente iguais entre si. Segundo Pereira et al. (2004), a firmeza do fruto está associada com a resistência ao despencamento, o que foi observado neste experimento, exceto para T1 e T3 (T5 a T7). Pimentel et al. (2010) observaram que as bananas PA42-44 ('Platina') apresentaram baixa firmeza da polpa e resistência ao despencamento em comparação com a 'Prata-Anã'.
Segundo Robinson e Galán Saúco (2010), a bananeira submetida ao estresse hídrico produz cachos e frutos pequenos, com redução da tonalidade do amarelo, podendo ficar escurecidos e com casca quebradiça. Cotrim et al. (2011), testando níveis controlados de água em mangueira, não constataram perdas significativas de produtividade e qualidade dos frutos. De acordo com Sotiropoulos et al. (2010), a utilização de $35 \%$ da ETc na fase de crescimento de pêssegos não influenciou a acidez e a firmeza dos mesmos, em comparação ao tratamento-controle (100\% da ETc). Perez-Pastor et al. (2009), avaliando frutos de damasco (Prunus armeniaca L.) produzidos com déficit hídrico, obtiveram valores mais elevados do teor de sólidos solúveis totais, acidez total em relação àqueles do tratamento-controle, porém a firmeza do fruto não foi influenciada. Cui et al. (2008) relataram que a firmeza, o teor de sólidos solúveis, a relação sólidos solúveis/acidez (ratio) e o conteúdo de vitamina $\mathrm{C}$ de jujuba (Ziziphus jujuba $\mathrm{L}$.) foram melhores nos frutos oriundos de plantas cultivadas sob irrigação com déficit hídrico.

O teor de sólidos solúveis foi maior nos frutos dos tratamentos T3 e T5, em que houve redução da lâmina de irrigação apenas na fase II, para 70\% e $85 \%$ da ETc. De forma inversa, em T4, onde houve redução da lâmina de irrigação apenas na fase III, para $70 \%$, os frutos apresentaram os menores valores de sst. Para este componente de qualidade, portanto, não foi necessária a utilização de lâminas de $100 \%$ da ETc na pré-floração (fase II), sendo que as lâminas de $70 \%$ e $85 \%$ mostram-se adequadas desde que não ocorra déficit durante o crescimento dos frutos (fase III).

Os valores de sólidos solúveis totais encontrados no presente trabalho foram superiores àquele observado por Oliveira (2010) - $14,45^{\circ}$ Brix - mas está dentro da faixa encontrada por Cerqueira et al. (2002) para frutos de diferentes genótipos de bananeira. Menor teor de sólidos solúveis pode ser um indicativo de amadurecimento mais lento dos frutos, já que a tendência é de aumento durante o amadurecimento. Os teores de sólidos solúveis produzidos em T3 foram maiores, podendo indicar amadurecimento mais acelerado. Os sólidos solúveis totais ( $\left.{ }^{\circ} \mathrm{Brix}\right)$ são usados como índice de maturidade e qualidade para alguns frutos, e indicam a quantidade de substâncias que se encontram dissolvidas no suco, sendo constituído, em sua maioria, por açúcares (MAIA et al. 1998; MEDINA, 1988). O teor de sólidos solúveis da banana aumenta até $27 \%$ no processo de maturação, com pequena diminuição quando a fruta está muito madura (BLEINROTH, 1995).

Houve diferença significativa entre os trata- 
mentos em relação à coloração da casca, apesar de visualmente todos os frutos apresentarem cor amarela (Tabela 4), correspondente ao estádio 6 de amadurecimento, de acordo com a escala de Loeseche (1950) usada na classificação da CEAGESP. De acordo com Álvares et al. (2003), a determinação da coloração dos frutos por colorímetro analisa as diferenças de cor da casca que aproxima espectralmente do padrão observado pelos olhos, com a vantagem de ser tridimensional, excluindo avaliações de cada observador (quando é feita apenas visualmente).

Considerando que o parâmetro L* (luminosidade ou brilho) da casca varia de 0 a 100 , e que valores baixos indicam casca opaca/ sem brilho e valores altos equivalem ao máximo brilho, todos os tratamentos apresentaram valores de médio a alto. A luminosidade da casca dos tratamentos T3, T4 e T5 foi maior, com valores 73,00; 70,00 e 73,12, respectivamente (Tabela 4). Já T6 foi o tratamento que apresentou casca dos frutos mais opaca, ou seja, com menos brilho.
Os frutos de T6 foram também os que apresentaram menor intensidade da coloração amarela (acinzentada), ou seja, com valores mais baixos de croma $\left(\mathrm{C}^{*}\right)$ (Tabela 4). Quanto mais baixos estes valores, mais impura é a cor.

A tonalidade da cor, representada pelo parâmetro ${ }^{\circ}$ hue (Tabela 4), de todos os frutos apresentou-se dentro da faixa angular da coloração amarela $\left(90^{\circ}\right)$. Aqueles produzidos sem déficit hídrico (T7), assim como T1 e T5 (redução de $45 \%$ e $25 \%$ da ETc na fase II, respectivamente), apresentaram maior valor, indicando casca de coloração amarela mais intensa. De acordo com a preferência dos consumidores entrevistados por Matsuura et al. (2004), as cores da casca preferidas foram a amarelo média e a amarelo-escura, totalizando $74,6 \%$ da preferência.

Segundo Robinson e Galán Saúco (2010), se apenas $30 \%$ da água requerida para irrigar o bananal está disponível, é melhor irrigar 30\% da melhor parte do bananal com toda a água demandada e abandonar o restante da área, que subirrigar toda a área.

TABELA 1-Análise de variância para massa fresca (mf), comprimento (comp), diâmetro (diâm), polpa/ casca (pc), resistência ao despencamento (rd), firmeza (fir) e sólidos solúveis totais (sst) de bananas 'PA 42-44', produzidas sob regulação do déficit de irrigação no norte de Minas Gerais.

\begin{tabular}{|c|c|c|c|c|c|c|c|c|}
\hline Fontes de Variacão & GL & $\mathrm{mf}$ & $\begin{array}{l}\text { Quadr } \\
\text { comp }\end{array}$ & $\begin{array}{l}\text { Médio } \\
\text { diâm }^{1}\end{array}$ & $\mathrm{pc}$ & $\mathrm{rd}^{1}$ & fir & sst \\
\hline Tratamentos & 6 & $3047,7 *$ & $17,6^{*}$ & $0,89 \mathrm{E}^{-02 *}$ & $0,84 *$ & $0,63 *$ & \multicolumn{2}{|c|}{$6,41 * \quad 0,65$} \\
\hline Resíduo & 49 & 61,8 & 0,34 & $0,18 \mathrm{E}^{-03}$ & $0,81 \mathrm{E}^{-02}$ & $0,32 \mathrm{E}^{-01}$ & 0,62 & $0,15 \mathrm{E}^{-01}$ \\
\hline Total & 56 & & & & & & & \\
\hline $\mathrm{CV}(\%)$ & & 5,9 & 3,0 & 1,0 & 4,35 & 19,8 & 16,2 & 0,6 \\
\hline
\end{tabular}

* Significativo a $5 \%$ pelo teste $\mathrm{F}$.

1. Dados transformados para $\log \mathrm{x}$.

TABELA 2-Análise de variância para luminosidade $\left(\mathrm{L}^{*}\right)$, cromaticidade $\left(\mathrm{C}^{*}\right)$ e ângulo de tonalidade $\left({ }^{\circ} \mathrm{Hue}\right)$ de bananas 'PA 42-44', produzidas sob regulação do déficit de irrigação no norte de Minas Gerais.

\begin{tabular}{lcccc}
\hline & \multicolumn{4}{c}{ Quadrado Médio } \\
Fontes de Variação & GL & luminosidade & cromaticidade & ângulo de tonalidade \\
\hline Tratamentos & 6 & $146,0^{*}$ & $71,58^{*}$ & $41,92^{*}$ \\
Resíduo & 49 & 9,58 & 10,62 & 1,93 \\
\hline Total & 56 & & & \\
\hline CV $(\%)$ & & 4,5 & 7,0 & 1,48 \\
\hline
\end{tabular}

*significativo a $5 \%$ pelo teste $\mathrm{F}$. 
TABELA 3 - Caracterização pós-colheita de bananas 'PA 42-44', produzidas sob regulação do déficit de irrigação no norte de Minas Gerais.

\begin{tabular}{lccccccc}
\hline Características & $\mathrm{T} 1$ & $\mathrm{~T} 2$ & $\mathrm{~T} 3$ & $\mathrm{~T} 4$ & $\mathrm{~T} 5$ & $\mathrm{~T} 6$ & $\mathrm{~T} 7$ \\
\hline Massa (g) & $142,7 \mathrm{~B}$ & $124,5 \mathrm{C}$ & $115,0 \mathrm{C}$ & $116,8 \mathrm{C}$ & $143,4 \mathrm{~B}$ & $118,3 \mathrm{C}$ & $167,8 \mathrm{~A}$ \\
Comprimento do Fruto (cm) & $19,1 \mathrm{CD}$ & $18,4 \mathrm{DE}$ & $20,0 \mathrm{~B}$ & $17,1 \mathrm{~F}$ & $19,4 \mathrm{BC}$ & $18,1 \mathrm{E}$ & $21,7 \mathrm{~A}$ \\
Diâmetro do Fruto (cm) & $39,1 \mathrm{~B}$ & $39,2 \mathrm{~B}$ & $38,4 \mathrm{~B}$ & $38,2 \mathrm{~B}$ & $39,1 \mathrm{~B}$ & $39,9 \mathrm{~B}$ & $45,1 \mathrm{~A}$ \\
Polpa/Casca & $1,78 \mathrm{E}$ & $1,99 \mathrm{D}$ & $2,36 \mathrm{~B}$ & $2,14 \mathrm{C}$ & $2,00 \mathrm{CD}$ & $2,57 \mathrm{~A}$ & $1,63 \mathrm{~F}$ \\
Resistência ao & & & & & & & \\
Despencamento (N) & $11,52 \mathrm{BC}$ & $23,82 \mathrm{~A}$ & $15,11 \mathrm{~B}$ & $3,82 \mathrm{D}$ & $6,14 \mathrm{CD}$ & $5,77 \mathrm{CD}$ & $7,37 \mathrm{CD}$ \\
Firmeza (N) & 4,46BCD & $5,58 \mathrm{AB}$ & $6,09 \mathrm{~A}$ & $5,46 \mathrm{ABC}$ & $4,25 \mathrm{CD}$ & $4,49 \mathrm{BCD}$ & $3,54 \mathrm{D}$ \\
Sólidos Solúveis Totais ('Brix) & 21,80B & 21,54B & 22,47A & 21,11C & $21,81 \mathrm{~B}$ & $21,75 \mathrm{~B}$ & $21,76 \mathrm{~B}$ \\
\hline
\end{tabular}

Médias seguidas de mesma letra na linha não diferem significativamente, pelo teste de Tukey, a 5\% de significância.

TABELA 4- Caracterização pós-colheita da coloração da casca de bananas 'PA 42-44', produzidas sob regulação do déficit de irrigação no norte de Minas Gerais.

\begin{tabular}{lccccccc}
\hline Características & $\mathrm{T} 1$ & $\mathrm{~T} 2$ & $\mathrm{~T} 3$ & $\mathrm{~T} 4$ & $\mathrm{~T} 5$ & $\mathrm{~T} 6$ & $\mathrm{~T} 7$ \\
\hline Luminosidade $\left(\mathrm{L}^{*}\right)$ & $66,37 \mathrm{~B}$ & $67,75 \mathrm{~B}$ & $73,00 \mathrm{~A}$ & $70,00 \mathrm{AB}$ & $73,12 \mathrm{~A}$ & $60,75 \mathrm{C}$ & $67,75 \mathrm{~B}$ \\
Cromaticidade $\left(\mathrm{C}^{*}\right)$ & $44,25 \mathrm{BC}$ & $47,75 \mathrm{AB}$ & $46,12 \mathrm{ABC}$ & $48,12 \mathrm{AB}$ & $50,87 \mathrm{~A}$ & $41,50 \mathrm{C}$ & $46,87 \mathrm{AB}$ \\
Ângulo de Tonalidade $\left({ }^{\circ} \mathrm{Hue}\right)$ & $95,62 \mathrm{AB}$ & $93,87 \mathrm{~B}$ & $94,12 \mathrm{~B}$ & $93,50 \mathrm{~B}$ & $95,50 \mathrm{AB}$ & $90,25 \mathrm{C}$ & $97,62 \mathrm{~A}$ \\
\hline
\end{tabular}

Médias seguidas de mesma letra na linha não diferem significativamente, pelo teste de Tukey, a 5\% de significância.

\section{CONCLUSÕES}

1-Para a maioria das características pós-colheita de bananas PA42-44 (Platina) estudadas, a ocorrência de déficit hídrico na fase III (da floração à colheita) é mais prejudicial que na fase II (entre diferenciação floral e a floração).

2-Todas as características de qualidade e rendimento estão associadas à ausência de déficit hídrico em todas as fases da PA42-44 (Platina), exceto a resistência ao despencamento e firmeza. Este resultado reforça a necessidade de cuidados especiais no manejo da fruta na pós-colheita, principalmente com relação às temperaturas de armazenamento.

\section{REFERÊNCIAS}

ALLEN, R. G.; PEREIRA, L. S.; RAES, D.; SMITH, $M$. Crop evapotranspiration: guidelines for computing crop water requirements. Rome: FAO, 1998. 300p. (Irrigation and Dranaige Paper, 56).

ÁlVARES, V. de S.; CORRÊA, P.C.; VIEIRA, G.; FINGER, F.L.; AGNESINI, R.V. Análise da coloração da casca de banana prata tratada com etileno exógeno pelo método químico e instrumental. Revista Brasileira de Produtos Agroindustriais, Campina Grande, v.5, n.2, p.155-160, 2003.
BLEINROTH, E. W. Banana: cultura, matéria-prima, processamento e aspectos econômicos. 2.ed. rev. e ampl. Campinas: I TAL, 1995. 302 p.

BORGES, R. de S.; SILVA, S. de O. e.; OLIVEIRA, F. T. de.; ROBERTO, S. R. Avaliação de genótipos de bananeira no Norte do Estado do Paraná. Comunicação Científica. Revista Brasileira de Fruticultura, Jaboticabal, v. 33, n. 1, p. 291-296, 2011.

CERQUEIRA, R.C.; OLIVEIRA SILVA, S. de; MEDINA, V.M. Características pós-colheita de frutos de genótipos de bananeira (Musa spp). Revista Brasileira de Fruticultura, Jaboticabal, v. 24, n. 3, p. $654-657,2002$.

CORBEÑA RUIZ, G. A. Relação entre componentes da parede celular e atividade enzimática no pedicelo e a suscetibilidade de bananas ao despencamento natural. 2003. 48 f. Dissertação (Mestrado em Fitotecnia) - Universidade Federal de Viçosa, Viçosa, 2003.

COTRIM, C. E.; COELHO FILHO, M. A.; COELHO, E. F.; RAMOS, M. M., CECON, P. R. Regulated deficit irrigation and tommy atkins mango orchard productivity under microsprinkling in brazilian semi arid. Engenharia Agrícola, Jaboticabal, v.31, n.6, p.1052-1063, 2011. 
CUI, N.B.; DU, T.S.; KANG, S.Z.; LI, F.S.; ZHANG, J.H.; WANG, M.X.; LI, Z.J. Regulated deficit irrigation improved fruit quality and water use efficiency in pear-jujube trees. Agricultural Water Management, Amsterdam, v.95, n. 4, p.489-497. 2008.

DAMATTO JR, E. R.; CAMPOS, A. J.de; MANOEL, L.; MOREIRA, G. C.; LEONEL, S.; EVANGELISTA, R. M. Produção e caracterização de frutos de bananeira 'prata-anã' e 'prata-zulu'. Revista Brasileira de Fruticultura, Jaboticabal, v. 27, n. 3, p. 440-443, 2005.

DOMINGO, R.; RUIZ-SÁNCHEZ, M.C.; SÁNCHEZ-BLANCO, M.J.; TORRECILLAS, A. Water relations, growth and yield of fino lemon trees under regulated deficit irrigation. Irrigation Science, New York, v.16, p.115-123, 1996.

DONATO, S.L.R. Comportamento de variedades e híbridos de bananeira (Musa spp.), em primeiro ciclo de produção no Sudoeste da Bahia, região de Guanambi. 2003. 115 f. Dissertação (Mestrado em Ciência e Tecnologia de Sementes) - Faculdade de Agronomia "Eliseu Maciel", Universidade Federal de Pelotas, Pelotas, 2003.

DONATO, S.L.R.; ARANTES, A. de M.; SILVA, S. de O.; CORDEIRO, Z.J.M. Comportamento fitotécnico da bananeira 'Prata-Anã' e de seus híbridos. Pesquisa Agropecuária Brasileira, Brasília, v.44, n.12, p.1608-1615, 2009.

DONATO, S. L. R.; OLIVEIRA e SILVA, S. de.; LUCCA FILHO, O. A.; LIMA, M. B.; DOMINGUES, H.; ALVES, J. da S. Comportamento de variedades e híbridos de bananeira (Musa spp.), em dois ciclos de produção no sudoeste da Bahia. Comunicação Científica Revista Brasileira de Fruticultura, Jaboticabal, v. 28, n. 1, p. 139-144, 2006.

ESGUERRA, E.B.; HILARIO, D.C.R.; ABSULIO, W.L. Controlo finger drop in 'Latundan' banana (Musa acuminata AA group) with preharvest calcium spray. Acta Horticulturae, The Hague, v.837, p. 167-170, 2009.

FRUTISSÉRIES. Banana: Minas Gerais. Brasília: Ministério da Integração Nacional, 2000. (Boletim, 6).
GONZÁLEZ-ALTOZANO, P.; CASTEL, J.R. Regulated deficit irrigation in 'Clementin a Nules' citrus tree. I Yield nad fruit quality effects. Journal of Horticultural Science \& Biotechnology, Ashford, v. 74, n.6, p.706-713, 1999.

INSTITUTO ADOLFO LUTZ. Normas analíticas do Instituto Adolfo Lutz. Métodos químicos e físicos de análise de alimentos. 3. ed. São Paulo, 1987.

JESUS, S.C.; FOLEGATTI, M. I. da S.; MATSUURA, F. C. A. U.; CARDOSO, R.L. Caracterização física e química de frutos de diferentes genótipos de bananeira. Bragantia, Campinas, v. 63, n.3, p. 315-323, 2004.

LIMA, M.B.; SILVA, S.O.; ALVES, J.S. Comportamento de variedades e híbridos de bananeira em Petrolina. In: CONGRESSO BRASILEIRO DE FRUTICULTURA, 18., 2004, Florianópolis. Anais... Florianópolis: Sociedade Brasileira de Fruticultura. Disponível em: $<\underline{\mathrm{http}}$ //www.sbfruti.com. br/anai xviii cbf/resumos/T0404-396.pdf $>$. Acesso em: 05 jan.2010.

LINS, R.D. Avaliação de genótipos de bananeira em dois ciclos de produção no município de Uma, BA. 2005. 55 f. Dissertação (Mestrado em Ciências Agrárias) - Universidade Federal da Bahia, Cruz das Almas, 2005.

LOESECKE, H.W.V. Bananas: chemistry, physiology, and technology. New York: Chapman and Hall, 1950. $189 \mathrm{p}$

MAIA, G.A.; OLIVEIRA, G.S.F.; FIGUEIREDO, R.W.F.; GUIMARÃES, A.C.L. Tecnologia em processamento de sucos e polpas tropicais. Brasília: ABEAS, 1998. v.1, p.104.

MARQUES, P. R. R.; DONATO, S.L.R.; PEREIRA, M. C. T.; COELHO, E. F.; ARANTES, A. de M. Características Agronômicas de bananeiras tipo Prata sob diferentes sistemas de irrigação. Pesquisa Agropecuária Brasileira, Brasília, v.46, n.8, p.852859,2011

MATSUURA, F. C. A. U.; COSTA, J. I. P. da; FOLEGATTI, M. I. da S. Marketing de banana: preferências do consumidor quanto aos atributos de qualidade dos frutos. Revista Brasileira de Fruticultura, Jaboticabal, v. 26, n. 1, 2004. 
MATSUURA, F.C.A.U.; FOLEGATTI, M.I.S. Banana pós-colheita. Bahia: Embrapa Mandioca e Fruticultura, 2001.

MEDINA, J.C. Goiaba: cultura, matéria prima, processamento e aspectos econômicos. 2.ed. Campinas: ITAL, 1988. p.1-21. (Série Frutas Tropicais, 6).

MORAIS, P. L. D. de.; FILGUEIRAS, H. A. C.; PINHO, J. L. N. de.; ALVES, R. E. Ponto de colheita ideal de mangas 'Tommy Atkins' destinadas ao mercado europeu. Revista Brasileira de Fruticultura, Jaboticabal, v.24, n.3, p.671-675. 2002.

OLIVEIRA, C.G. de. Caracterização pós-colheita de banana prata-anã e seu híbrido PA42-44 armazenados sob refrigeração. 2010. $74 \mathrm{f}$. Dissertação (Mestrado em Produção Vegetal no Semiárido) Universidade Estadual de Montes Claros, Montes Claro, 2010.

OLIVEIRA, T.K.; LESSA, L.S.; SILVA, S. de O e; OLIVEIRA, J.P.de. Características agronômicas de genótipos de bananeira em três ciclos de produção em Rio Branco, AC. Pesquisa Agropecuária Brasileira, Brasília, v.43, n.8, p.1003-1010, 2008.

PEREIRA, M.C.T.; SALOMÃO, L.C.C.; SILVA, S. de O. e.; CECON, P.R.; PUSCHMANN, R.; JESUS, O. N. de.; CERQUEIRA, R.C. Susceptibilidade à queda natural e caracterização dos frutos de diversos genótipos de bananeiras. Revista Brasileira de Fruticultura, Jaboticabal, v.26, n.3, 2004.

PEREZ-PASTOR, A.; DOMINGO, R.; TORRECILLAS, A.; RUIZ-SANCHEZ, C. Response of apricot trees to deficit irrigation strategies. Irrigation Science, New York, v.27, p.231-242, 2009.
PIMENTEL, R. M. de A.; GUIMARÃES, F.N.; SANTOS, V. M. dos.; RESENDE, J. C. F. de. Qualidade pós-colheita dos genótipos de banana PA42-44 e Prata-Anã cultivados no Norte de Minas Gerais. Revista Brasileira de Fruticultura, Jaboticabal, v. 32, n. 2, 2010.

ROBINSON, J.C.; GALÁN SAÚCO, V. Bananas and plantains. $2^{\text {nd }}$ ed. Oxford: $C A B$ International, 2010. 311p. (Crop Production Science in Horticulturae Series, 19).

SAEG. Sistema para análises estatística., Versão 9.1. Viçosa: Fundação Arthur Bernardes, 2007.

SAENGPOOK, C.; KETSA, S.; VAN DOORN, W.G. Effects of relative humidity on banana fruit drop. Postharvest Biology and Technology, Amsterdam, v. 45, n.1, p. 151-154, 2007.

SILVA, D. F. P. da.; ROCHA, A.; MIZOBUTSI, G. P.; BARBOSA, R. L. Avaliação sensorial da cor da casca de banana 'Prata Anã'. Unimontes Científica, Montes Claros, v. 8, n.1, p. 69-74, 2006.

SILVA, S.O.; PEREIRA, L.V.; RODRIGUES, M.G.V. Variedades. Informe Agropecuário, Belo Horizonte, v.29, n.245, p.78-83, 2008.

SOTIROPOULOS, T.; KALFOUNTZOS, D.; ALEKSIOU, I.; KOTSOPOULOS, S.; KOUTINAS, N. Response of a clingstone peach cultivar to regulated deficit irrigation. Scientia Agricola, Piracicaba, v.67, n.2, p.164-169, 2010.

SOTO BALESTERO, M. Bananos: cultivo y comercialización. $2^{\text {nd }}$ ed. San José: Imprenta Lil, 2000. 1 CD-ROM. 